\title{
Screening Test of a New Pulsed Plasma Jet for Medical Application
}

\author{
Kerstin Horn, ${ }^{\mathrm{a},{ }^{\star}}$ Oliver Beier, ${ }^{\mathrm{a}}$ Cornelia Wiegand, ${ }^{\mathrm{b}}$ Abdelkhalil Laaouina, ${ }^{\mathrm{c}}$ Sarah \\ Fink, ${ }^{b}$ Andreas Pfuch, ${ }^{a}$ Arnd Schimanski, ${ }^{a}$ Bernd Grünler, ${ }^{a}$ \& Uta-Christina Hipler ${ }^{b}$ \\ alnnovent e.V., 07745 Jena, Germany; 'Department of Dermatology, University Hospital Center \\ Jena, 07740 Jena, Germany; ' Ernst-Abbe-University of Applied Sciences, 07745 Jena, Germany \\ *Address all correspondence to: Kerstin Horn, Innovent e.V., Prüssingstraße 27b, 07745 Jena, Germany; Tel.: +49 3641 \\ 2825 54; Fax +49 36412825 30, E-mail: kh1@innovent-jena.de
}

\begin{abstract}
Plasma sources in practice as medical devices must be certified according to strict safety standards. The present study analyzes the potential of a cold atmospheric pressure (CAP) jet for medical and specialized dermatological applications. We characterize plasma properties and investigate antimicrobial and cytotoxic effects. Plasma treatment of bacteria and fungi is performed using plasma mefenamic acid (MEF) (Tigres $\mathrm{GmbH}$; Marschacht, Germany) pulsed technology. To evaluate the effects on biological materials, plasma process gas, input power, and treatment time were varied. The same treatments were realized on threedimensional skin models to study cytotoxic effects. Treatment of bacteria and fungi with the plasma source of plasma MEF pulsed, with its cold potential-free plasma, shows a definite dependence on the kind of process gas used, plasma input power, and treatment time. Low plasma doses exhibit good cell compatibility for short, locally fixed treatment times. The CAP jet source of plasma MEF pulsed, using air or nitrogen as the process gas, seems to be suitable for medical and especially dermatological applications. In our study, it was possible to identify a range of useful therapeutic parameters with good antibacterial efficacy and without cytotoxic effects.
\end{abstract}

KEY WORDS: cold atmospheric pressure plasma, plasma characterization, antimicrobial effect, dermatology, skin model

\section{INTRODUCTION}

Cold atmospheric pressure (CAP) plasma is an innovative technology for technical surface modification, offering various interesting possibilities for human and medical engineering applications. ${ }^{1-6}$ Several studies have explored possible clinical uses. ${ }^{7-13}$ For instance, treatment of chronic, nonhealing wounds with atmospheric pressure plasma is a very promising, patient-friendly, and fast new method to achieve increased healing rates by reducing the microbiological burden. It may also be an option in the fight against resistant pathogens. However, the medical use of plasma sources requires profound physical characterization and biomedical investigations in relation to bactericidal and cytotoxic impacts to ensure efficacy and safety. ${ }^{14-19}$ Moreover, the application of plasma as a therapeutic device is closely connected with the development of CAP plasma sources for the treatment of small but deep cavities through wounds covering large areas of the body. Due to this variety in application range, it becomes clear that one plasma source cannot fulfill all requirements. ${ }^{20,21}$ 
The plasma source that was used in this project was developed based on plasma mefenamic acid (MEF) technology from Tigres $\mathrm{GmbH}$, Marschacht, Germany, an established industrial source for surface activation. ${ }^{22}$ The newly developed CAP jet works with a defined pulsed discharge and consequentially lower plasma temperatures. One part of the presented works includes temperature measurements in plasma-treated agar plates to investigate the relevant thermal impact of the plasma for dermatological applications. The main focus of the work was to study the bactericidal efficacy of the plasma based on an input power range featuring benign surface temperatures $<42^{\circ} \mathrm{C}$. In a next step, parameters with bactericidal effect were analyzed for cytotoxic influence using three-dimensional (3D) skin models to verify safety of the parameter set identified.

\section{MATERIALS AND MEIHODS}

\section{A. CAP Plasma}

Plasma is an energetic, activated gas that is characterized through a typical combination of reactive species (depending on the process gas used, e.g., reactive oxygen species [ROS] or reactive nitrogen species [RNS]), violet (V)-ultraviolet (UV) radiation, electrical fields, electrons and ions, visible light, and temperature.

The pulsed plasma jet is a specially designed device, wherein the plasma is generated by a direct-current pulsed electric barrier discharge, and the jet is directed onto the surface with the aid of compressed process gas. The single-nozzle type is usable for highprecision treatment. Various process gases can be used, defining the specific reactive species inside the plasma (such as ROS and RNS) that interact with biological material. ${ }^{22}$

Several basic plasma parameters were varied in this work to change and investigate the impact of plasma properties directly on the treated surface. We examined the following plasma parameters: process gas (nitrogen or air), input of electrical power, distance between nozzle and treated surface, and treatment time in cases of dot-like applications or the number of treatment runs with defined velocity and grid spacing for an areal regime.

\section{B. Plasma Characterization}

Plasma characterization is the basic requirement for application of a plasma source in the clinical setting. The identified plasma properties must be correlated to their biological effects; this is crucial for certification of any plasma source used in a medical device. For this study, the focus was on two investigations: (1) temperature measurements inside model substances carried out to determine the thermal impact of the jet plasma and (2) optical emission spectroscopy (OES) performed on the plasma itself, as previously reported. ${ }^{23}$

\section{Temperature Measurement}

Low thermal impact on treated surfaces is a basic criterion for direct medical application of plasma on human skin. For this study, a simple tissue model was created using agar as 
test medium. Inside, the agar thermocouples were located in defined distances of 1, 2, 3, and $4 \mathrm{~mm}$ below the surface. The maximum temperature was defined as $42^{\circ} \mathrm{C}$, which could not be exceeded during the plasma interaction to ensure good biocompatibility. With help of a data logger and type-K thermocouples, the tolerable plasma input power was determined for the plasma MEF pulsed. The schematic measurement setup is shown in Fig. 1. With this setup and the short reaction times of the thermocouples, temperature evaluation with time, of both a dot-like and areal plasma treatment, was measured. All four channels were recorded at the same time for each particular measuring point inside the agar.

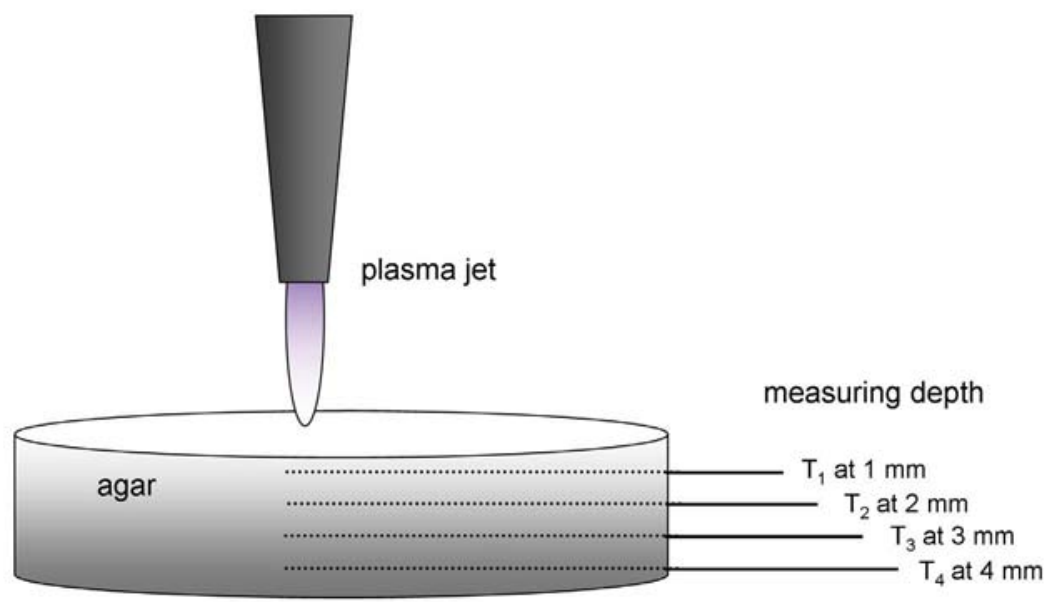

FIG. 1: Principle of temperature measurement in agar with thermocouples

\section{OES}

OES is a typical method for contact-free characterization of plasma constituents without manipulation of the plasma. In this study, the OES-system Emicon HR (PLASUS $\mathrm{GmbH}$; Mering, Germany) was used. Characteristics of this high-resolution measurement system are a wavelength range of $200-860 \mathrm{~nm}$ and a spectral resolution of 0.15 $\mathrm{nm} .{ }^{24}$ To accumulate sufficient radiation and signal intensities from the plasma jet, the integration times were set to $500 \mathrm{~ms}$ for nitrogen as process gas and $1 \mathrm{~s}$ for air. The optical head was positioned in line with the plasma jet but orientated inversely beneath to collect the radiation (with subsequent fiber optics leading to the spectrometer).

\section{A. Plasma Treatment}

\section{Treatment Regimes}

For treatments, we varied between dot-like and areal/flat treatment. Temperature measurements were realized with both approaches. Table 1 gives an overview of plasma 
and process parameters varied for dot-like treatments and Table 2 highlights areal treatment.

\section{Bacteria and Fungi}

Bactericidal effects of plasma treatment with different parameters were investigated in vitro using Pseudomonas aeruginosa (Gram-negative strain), Staphylococcus aureus (Gram-positive strain), and the yeast Candida albicans, as reported previously. ${ }^{2}$

Bacteria and fungi were cultivated on agar plates. In most cases, the plasma treatment was areal/flat as shown in Fig. 2 after a treatment with the plasma MEF system in its basic version, without an additional pulsed mod. A line spacing of $5 \mathrm{~mm}$ was used for visualization of the meandering treatment pattern.

TABLE 1: Plasma and process parameters for dot-like treatment

\begin{tabular}{cc}
\hline Treatment Parameter & Parameter Range \\
\hline Working gas & Air, nitrogen \\
Input power & $30,60,80,100,120 \mathrm{~W}$ \\
Treatment time & $5,10,15,20,25 \mathrm{~s}$ \\
Treatment distance & $10,15,20 \mathrm{~mm}$ \\
\hline
\end{tabular}

TABLE 2: Plasma and process parameters for areal/flat treatment

\begin{tabular}{cc}
\hline Treatment Parameter & Parameter Range \\
\hline Working gas & Air, nitrogen \\
Input power & $30,60,80,100,120 \mathrm{~W}$ \\
Treatment area/line spacing & nearly $30 \times 30 \mathrm{~mm} / 3 \mathrm{~mm}$ \\
Treatment velocity & $25 \mathrm{~mm} / \mathrm{s}$ \\
Number of treatments & $2,4,8,12 \mathrm{runs}$ \\
Treatment distance & $10,15,20 \mathrm{~mm}$ \\
\hline
\end{tabular}

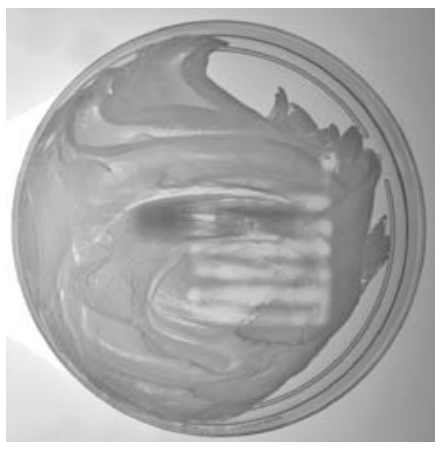

FIG. 2: Agar plate with microorganisms after plasma treatment with the plasma MEF system (in its basic version, without an additional pulsed mod) and meandering pattern (with a line spacing of $5 \mathrm{~mm}$ for visualization) 


\section{3D Skin Models}

To study possible cytotoxic plasma effects, the same treatments as described for bacteria and fungi were realized on 3D skin models, consisting of a keratinocyte-containing epidermal layer and a fibroblast/collagen dermal matrix. Plasma treatment of 3D skin models was carried out using inserts, as shown in Fig. 3.

\section{RESULTS}

\section{A. CAP Characteristics}

The most important plasma components for medical application are reactive species including ROS and RNS as well as (V)UV radiation. These feature the highest potential to affect cells and microorganisms alike. In addition, surface temperature is crucial for thermic destruction of biological tissues and cells. However, patients can feel discomfort due to locally increased temperature stress.

\section{Agar Temperature Measurements}

Dependence of agar temperatures for different penetration depths and plasma input powers is shown in Fig. 4. These are results for the dot-like local plasma treatment without movement of the plasma jet or substrate. The temperature values given in Fig. 4 have been measured in different measuring depths in the agar plate after $10 \mathrm{~s}$ of permanent plasma treatment ranging from $1 \mathrm{~mm}$ (T1) to $4 \mathrm{~mm}$ (T4). If a surface temperature $<42^{\circ} \mathrm{C}$ must be maintained, it is clear that the plasma input power has to be limited to $\sim 120 \mathrm{~W}$ using the plasma MEF pulsed.

Figure 5 shows another example for the temperature effect of a plasma treatment on agar, measured in depths of 1 and $2 \mathrm{~mm}$. Here, the agar substrates with embedded

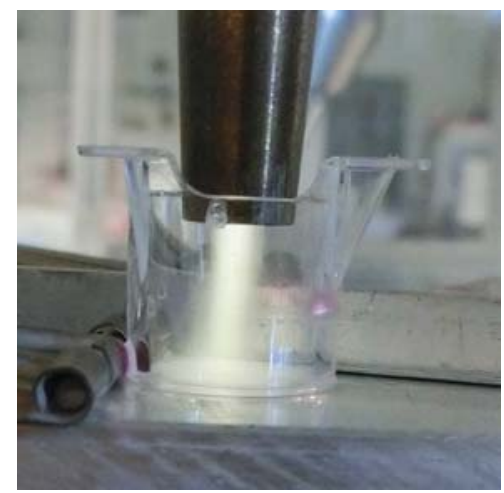

FIG. 3: Plasma treatment of 3D skin models in inserts. The example shows plasma MEF pulsed, with air as the working gas.

Volume 7, Issue 2, 2017 


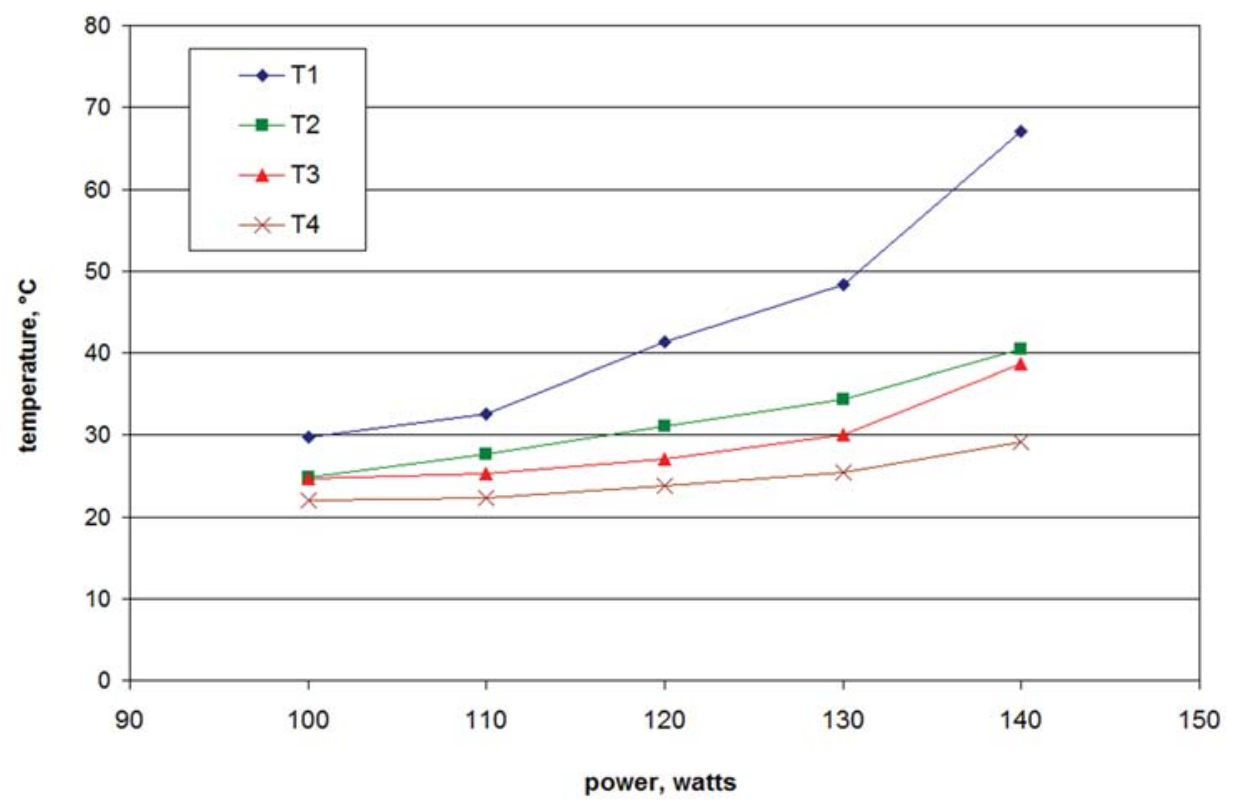

FIG. 4: Temperature measurement with the working gas $\mathrm{N}_{2}$ in different measuring depths, according to Fig. 1. The burner distance was kept at $10 \mathrm{~mm}$, local treatment time was fixed at 10 $\mathrm{s}$, and T1-T4 were the four measurement points placed $1-4 \mathrm{~mm}$, respectively, beneath the agar surface.

temperature measuring points were moved with constant velocity below the plasma burner with an overall eight treatment runs. The plasma input power was fixed at $100 \mathrm{~W}$. The resulting measured temperature profile demonstrates the maintenance of moderate temperature near the agar surface, too. Although with each treatment run the maximum temperature increases, the critical agar temperature of $42^{\circ} \mathrm{C}$ would not be reached for both measuring points beneath the surface at $1 \mathrm{~mm}$ (T1) and $2 \mathrm{~mm}(\mathrm{~T} 2)$.

\section{Reactive Plasma Species}

OES investigations were carried out for an electrical input power of $80 \mathrm{~W}$ with process gases air and nitrogen (using gas pressures of least 6 bar for the compressed gases). Figure 6 shows typical optical emission spectra of excited species for both gas types.

The spectrum for air shows distinct differences from nitrogen-driven jet plasmas. For air, both RNS and ROS species can typically be detected. The spectrum is dominated by excited nitrogen molecules $\left(\mathrm{N}_{2} *\right.$ is the second positive system between 290 and $410 \mathrm{~nm}$ ), NO* between 200 and $290 \mathrm{~nm}, \mathrm{O}^{*}$ at $777.4 \mathrm{~nm}$ and $844.6 \mathrm{~nm}$, and, in addition, small signals of $\mathrm{OH}^{*}$ can be deduced at $\sim 306-313 \mathrm{~nm}$. On the other hand, the nitrogen spectrum demonstrates exclusively reactive nitrogen species. These are the second positive system of $\mathrm{N}_{2}{ }^{*}$ (also found with air) and the first negative system of $\mathrm{N}_{2}{ }^{+}$ 


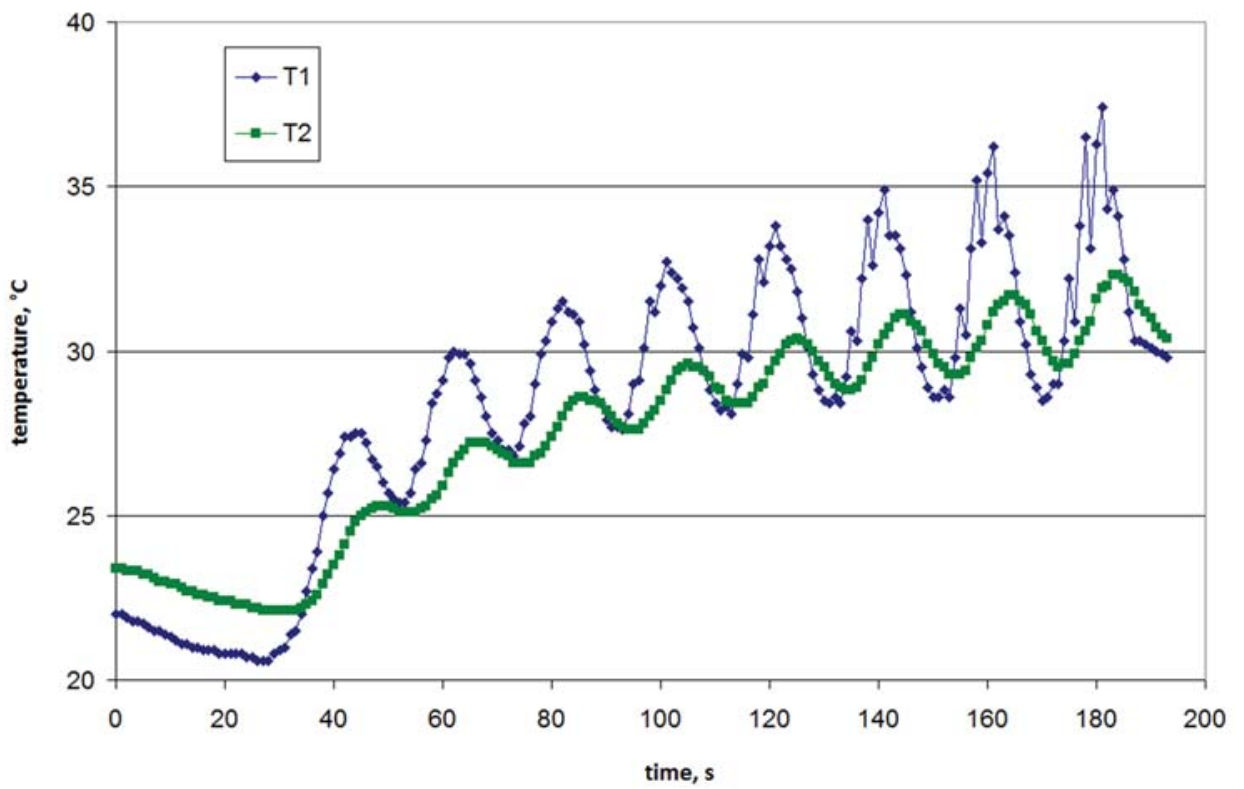

FIG. 5: Temperature measurement in different measuring depths, according to Fig. 1. Treatment distance was kept at $10 \mathrm{~mm}$, the number of treatments was eight runs, plasma input power was fixed at $100 \mathrm{~W}$, and $\mathrm{N}_{2}$ was used as the working gas. All other parameters were according to Table 2. T1 and T2 were the measurement points at 1 and $2 \mathrm{~mm}$, respectively, beneath the agar surface.

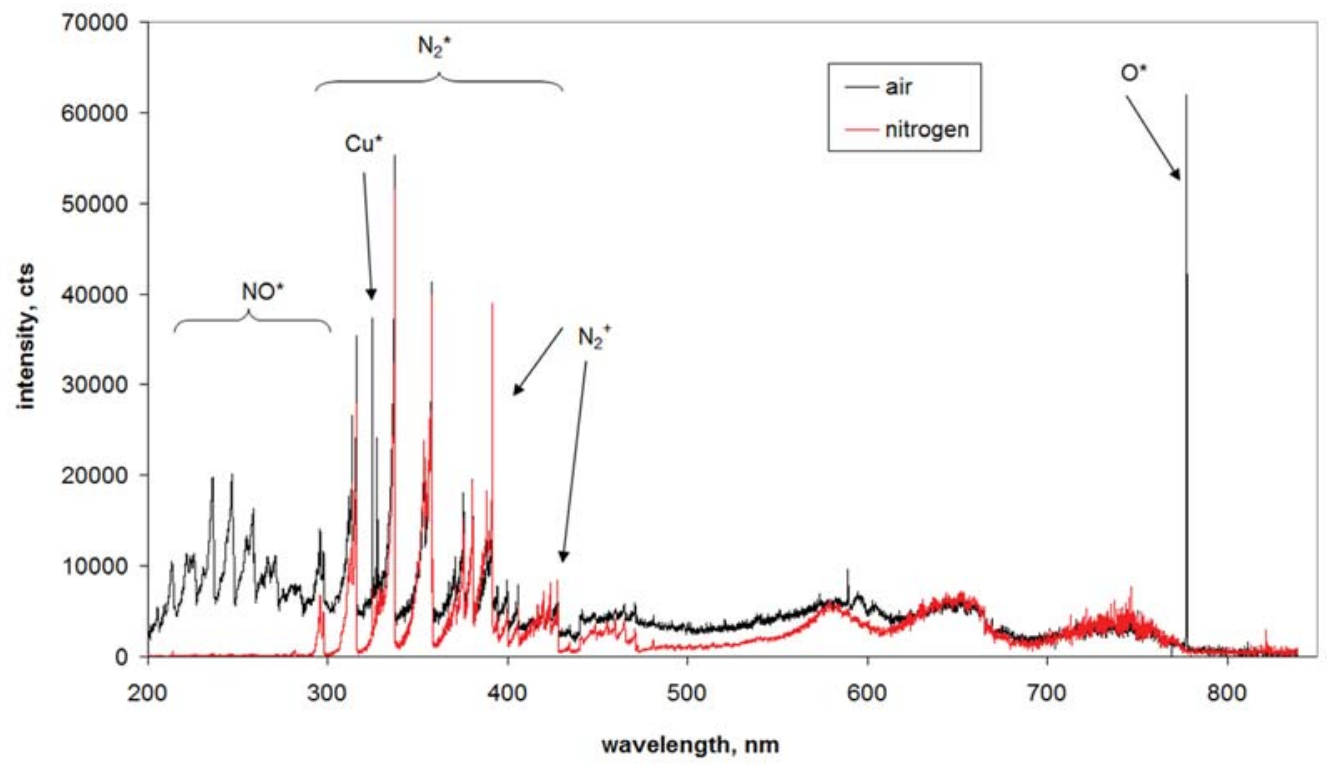

FIG. 6: Optical emission spectra of air- and nitrogen-based plasma 
between 390 and $430 \mathrm{~nm}$. Both spectra further show signals from two copper lines at 324.7 and $327.4 \mathrm{~nm}$. The copper can be correlated to a metallic high-voltage electrode that consists of brass. Hence, a certain sputtering effect of the electrode material can be assumed.

\section{B. Effects of CAP on Bacteria and Fungi}

A distinct microbiocidal effect of the plasma source could be observed against $P$. aeruginosa, S. aureus, and C. albicans. We found differences in plasma impact depending on microorganism species and treatment parameters, such as kind of process gas, electrical input power, treatment time, and distance to surface treated.

Figure 7 shows the bactericidal effect of plasma on $P$. aeruginosa depending on electrical input power and the number of treatment runs for an areal/flat treatment. Increase number of runs correlates with the extension of treatment time. Moreover, an extension of the bactericidal effect beyond the area treated was observed for nitrogen with increasing input power in the case of $P$. aeruginosa, also noticeable in the loss of the green coloring in the bacteria strain.

\begin{tabular}{|l|l|l|l|l|l|}
\hline & Power $30 \mathrm{~W}$ & Power $60 \mathrm{~W}$ & Power $80 \mathrm{~W}$ & Power $100 \mathrm{~W}$ & Power $120 \mathrm{~W}$ \\
\hline 2 & & & & \\
$\mathrm{R}$ & & & & \\
$\mathrm{u}$ \\
$\mathrm{n}$ \\
$\mathrm{s}$
\end{tabular}

FIG. 7: Plasma treatment of $P$. aeruginosa under variation of electrical input power and number of runs. The process gas was nitrogen, the treatment was areal, and the distance between nozzle and treated surface was $10 \mathrm{~mm}$. 
dot-like treatment
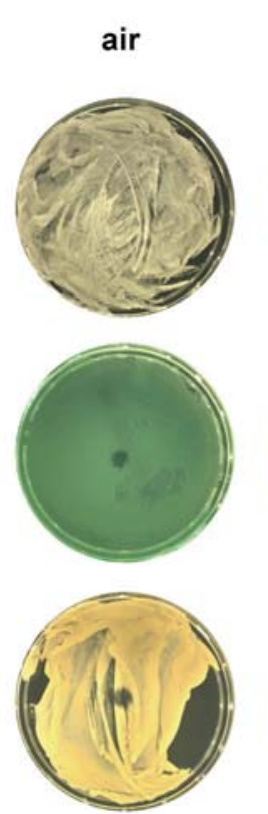
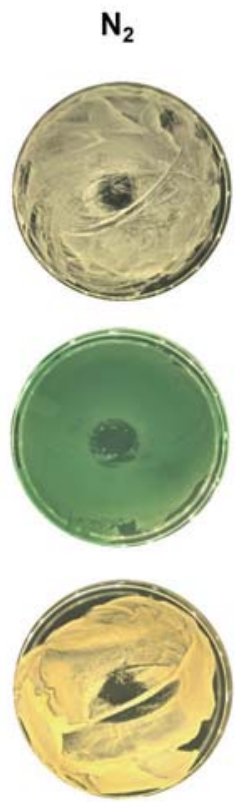

Candida albicans
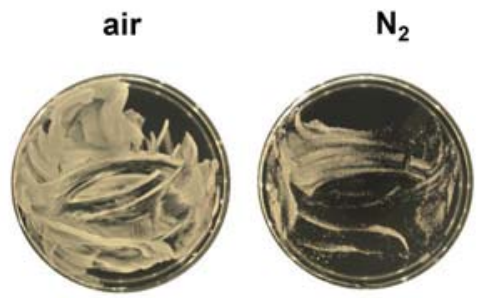

Pseudomonas aeruginosa (gram -)
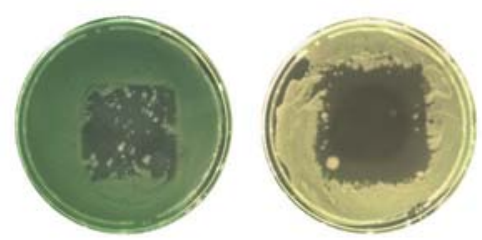

Staphylococcus aureus $($ gram +$)$
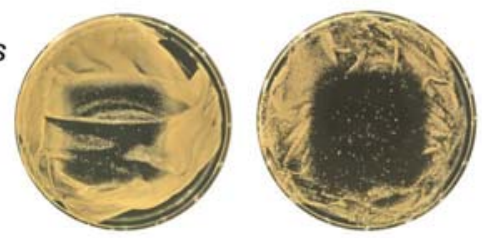

FIG. 8: Plasma treatment of various microorganisms. Process gases were air and nitrogen, treatments were dot-like and areal, electrical power was set to $100 \mathrm{~W}$, dot-like treatment lasted 10 $\mathrm{s}$, the number of areal treatments was eight runs, and the distance between nozzle and treated surface was $10 \mathrm{~mm}$.

Figure 8 demonstrates the effect of plasma treatment on the two bacteria strains and the yeast. A distinct difference in plasma efficacy was observed. Using the process gas air, C. albicans remained more or less unaffected, whereas air-based plasma exhibited a significant impact on $P$. aeruginosa and $S$. aureus. Nitrogen as process gas demonstrated a distinct bactericidal and fungicidal effect. Furthermore, differences in the bactericidal effect of air and nitrogen as process gases for the same treated area are apparent, with nitrogen exhibiting a greater microbiocidal effect.

\section{Dose-Dependent Effects of CAP on 3D Skin Models: Histological Changes}

Cytocompatibility of plasma from the pulsed plasma MEF source was found to be strongly dependent on input power and treatment time as well as on the process gas used (Fig. 9). At low doses, plasma treatment was well tolerated and histological sections appeared to be comparable to untreated controls. However, increased power or treatment time led to distinct damage in the epidermal layer that reached as far as the dermal layer. Injured fibroblasts were recognized by their roundish appearance and dark color, whereas the epidermis of the 3D skin model showed a virtually burned surface. 
A

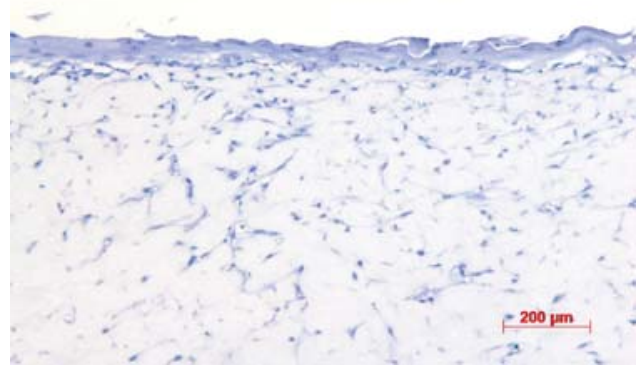

$\mathrm{C}$

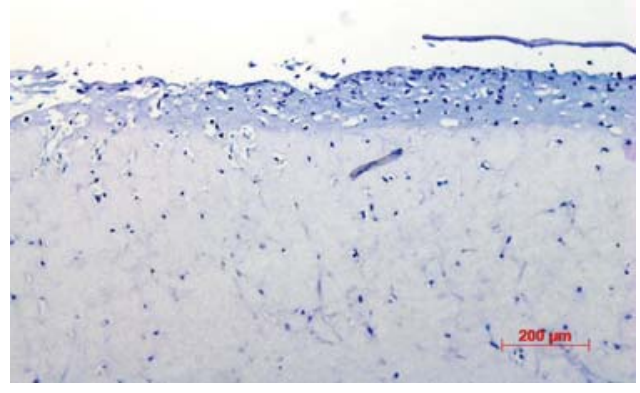

B

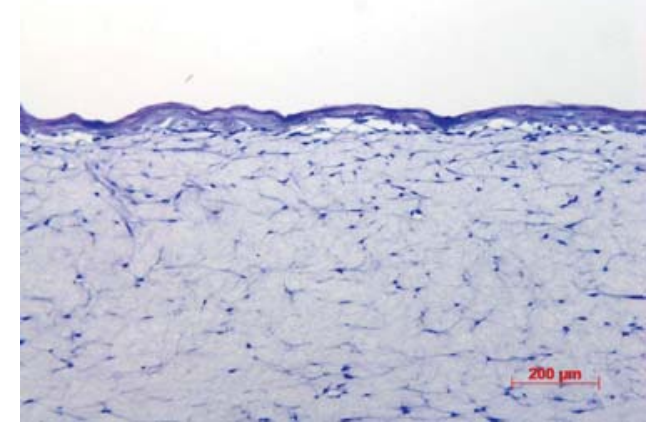

$\mathrm{D}$

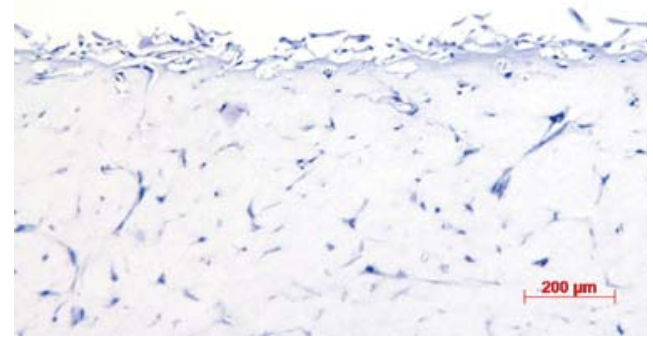

FIG. 9: Evaluation of the cytocompatibility of plasma treatment using 3D skin models and histological examination. (A) The untreated control exhibits normal epidermal and dermal layers. (B) Low-plasma doses (such as $30 \mathrm{~W}$ per $2 \mathrm{~s}$ ) demonstrate effective tissue compatibility in the 3D skin model. (C) The increase of input power $(60 \mathrm{~W})$ and treatment time $(10 \mathrm{~s})$ using nitrogen as the process gas induced toxic effects. (D) At the same doses ( $60 \mathrm{~W}$ per $10 \mathrm{~s}$ ), air-based plasma displayed a slightly higher cytotoxic potential when compared to nitrogen.

In general, air-based plasma exhibited a slightly higher cytotoxic potential, but plasma generated from nitrogen as process gas was better tolerated.

\section{DISCUSSION}

Preliminary results on the comprehensive investigation of the plasma MEF source in pulsed application mode showed suitable microbiocidal effects up to $120 \mathrm{~W}$, accompanied by only moderate temperature stress on the treated area. A common areal/flat plasma treatment with linear or meandering movement of the plasma jet above the treated material exhibited only slight temperature stress. It was further confirmed that the process gas used has an important role in effects observed. This is in accordance with previously published results for the plasma MEF system in its basic version, without 
an additional pulsed mod. ${ }^{2}$ Nitrogen demonstrated a significantly higher antimicrobial impact compared to air. Moreover, plasma generated from nitrogen as process gas was better tolerated compared to air-based plasma, which exhibited a slightly higher cytotoxic potential.

The focus of the study was to clarify the influencing mechanisms of MEF-plasma efficacy and to identify the plasma parameters for maximum therapeutic effect with minimal cytotoxic stress. Such plasma parameters could be identified for the plasma MEF pulsed. No visible damage of 3D skin models occurred using a plasma input power of up to $60 \mathrm{~W}$ for short treatment times, whereas definite antimicrobial activity against bacteria and yeast test strains was observed.

Future experiments will concentrate on dose- and time-dependent gene expression analysis and quantification of interleukin release, as in the case for the standard plasma MEF system, as published elsewhere. ${ }^{19}$

\section{CONCLUSIONS}

It can be assumed that different plasma sources for specific medical and cosmetic applications or, in general, medical engineering will be available in a few years after appropriate clinical studies and certification procedures are performed. Many designs for plasma sources as medical devices are conceivable and range from local jets by areal sources to flat plasma "patches." It will be important to investigate different kinds of plasma sources with reference to correlation among plasma species detected, antimicrobial effect, and subsequent identification of suitable therapeutic windows with low plasma temperature, antimicrobial activity, and high cell compatibility. This will build on the fundamentals for clinical studies and recommendations for CAP treatment, for instance, in dermatology.

For plasma MEF pulsed, an intensive bactericidal impact using nitrogen as the process gas can be confirmed. Furthermore, there seems to be a realistic therapeutic window for dermatological applications up to a plasma input power of $60 \mathrm{~W}$ without negative influence on the surrounding tissue. However, before using the pulsed plasma MEF jet in dermatological routine, it will be necessary to modify the plasma source by reducing the process gas flow, realizing a defined treatment distance and treatment power, and optimizing treatment time and treatment number for various dermatological applications.

\section{ACKNOWHGGENT}

We thank the German Federal Ministry for Economic Affairs and Energy (BMWi) for financial support under Grant No. INNO-KOM MF140070.

\section{REFERENCES}

1. Kong MG, Kroesen G, Morfill G, Nosenko T, Shimizu T, van Dijk J, Zimmermann JL. Plasma medicine: An introductory review. New J Phys. 2009;11:115012.

Volume 7, Issue 2, 2017 
2. Wiegand C, Beier O, Horn K, Pfuch A, Tölke T, Hipler UC, Schimanski A. Antimicrobial impact of cold atmospheric pressure plasma on medical critical yeasts and bacteria cultures. Skin Pharmacol Physiol. 2014;27:25-35.

3. Isbary G, Shimizu T, Li YF, Stolz W, Thomas HM, Morfill GE, Zimmermann JL. Cold atmospheric plasma devices for medical issues. Expert Rev Med Devices. 2013;10(3):367-77.

4. Duske K, Wegner K, Donnert M, Kunert U, Podbielski A, Kreikemeyer B, Gerling T, Weltmann KD, Nebe B, Bader R. Comparative in vitro study of different atmospheric pressure plasma jets concerning their antimicrobial potential and cellular reaction. Plasma Process Polym. 2015;12:1050-60.

5. von Woedtke T. Grundlagen der Plasmamedizin. Der MKG-Chirurg. 2016;9:246-54. DOI 10.1007/ s12285-016-0075-0.

6. Metelmann HR, von Woedtke T, Weltmann KD, editors. Plasmamedizin. Berlin: Springer; 2016.

7. Brehmer F, Haenssle HA, Daeschlein G, Ahmed R, Pfeiffer S, Görlitz A, Simon D, Schön MP, Wandke D, Emmert S. Alleviation of chronic venous leg ulcers with a hand-held dielectric barrier discharge plasma generator (PlasmaDerm ${ }^{\circledR}$ VU-2010): Results of a monocentric, two-armed, open, prospective, randomized and controlled trial (NCT01415622). J Eur Acad Dermatol Venereol. 2015 Jan;29(1): 148-55.

8. Isbary G, Stolza W, Shimizu T, Monetti R, Bunk W, Schmidt HU, Morfill GE, Klämpfl TG, Steffes B, Thomas HM, Heinlin J, Karrer S, Landthaler M, Zimmermann JL. Cold atmospheric argon plasma treatment may accelerate wound healing in chronic wounds: Results of an open retrospective randomized controlled study in vivo. Clin Plasma Med. 2013;1:25-30.

9. Kisch T, Helmke A, Schleusser S, Song J, Liodaki E, Stang FH, Mailaender P, Kraemer R. Improvement of cutaneous microcirculation by cold atmospheric plasma (CAP): Results of a controlled, prospective cohort study. Microvasc Res. 2016;104:55-62.

10. Bekeschus S, Winterbourn CC, Kolata J, Masur K, Hasse S, Bröker BM, Parker HA. Neutrophil extracellular trap formation is elicited in response to cold physical plasma. J Leukocyte Biol. 2016;100: 791-9.

11. Heinlin J, Zimmermann JL, Zeman F, Bunk W, Isbary G, Landthaler M, Maisch T, Monetti R, Morfill G, Shimizu T, Steinbauer J, Stolz W, Karrer S. Randomized placebo-controlled human pilot study of cold atmospheric argon plasma on skin graft donor sites. Wound Rep Reg. 2013;21:800-7.

12. Isbary G, Morfill G, Schmidt HU, Georgi M, Ramrath K, Heinlin J, Karrer S, Landthaler M, Shimizu T, Steffes B, Bunk W, Monetti R, Zimmermann JL, Pompl R, Stolz W. A first prospective randomized controlled trial to decrease bacterial load using cold atmospheric argon plasma on chronic wounds in patients. Br J Dermatol. 2010;163:78-82.

13. Isbary G, Heinlin J, Shimizu T, Zimmermann JL, Morfill G, Schmidt HU, Monetti R, Steffes B, Bunk W, Li Y, Klaempfl T, Karrer S, Landthaler M, Stolz W. Successful and safe use of 2 min cold atmospheric argon plasma in chronic wounds: Results of a randomized controlled trial. Br J Dermatol. 2012;167:404-10.

14. Fridman G, Brooks AD, Balasubramanian M, Fridman A, Gutsol A, Vasilets VN, Ayan H, Friedman G. Comparison of direct and indirect effects of non-thermal atmospheric pressure plasma on bacteria. Plasma Process Polym. 2007;4:370-5.

15. Kim HY, Kang SK, Park SM, Jung HY, Choi BH, Sim JY, Lee JK. Characterization and effects of Ar/ air microwave plasma on wound healing. Plasma Process Polym. 2015;12:1423-34.

16. Jablonowski H, Bussiahn R, Hammer MU, Weltmann KD, von Woedtke T, Reuter S. Impact of plasma jet vacuum ultraviolet radiation on reactive oxygen species generation in bio-relevant liquids. Phys Plasmas. 2015;22:122008.

17. Lin A, Chernets N, Han J, Alicea Y, Dobrynin D, Fridman G, Freeman TA, Fridman A, Miller V. Nonequilibrium dielectric barrier discharge treatment of mesenchymal stem cells: Charges and reactive oxygen species play the major role in cell death. Plasma Process Polym. 2015;12:1117-27.

18. Schmidt-Bleker A, Winter J, Bösel A, Reuter S, Weltmann KD. On the plasma chemistry of a cold atmospheric argon plasma jet with shielding gas device. Plasma Sources Sci Technol. 2016;25:015005. 
19. Wiegand C, Fink S, Beier O, Horn K, Pfuch A, Schimanski A, Grünler B, Hipler UC, Elsner P. Doseand time-dependent cellular effects of cold atmospheric pressure plasma evaluated in 3D skin models. Skin Pharmacol Physiol. 2016;29:257-65.

20. Boxhammer V. Development of a safe therapeutic window for cold atmospheric plasma treatments [dissertation]. München (Germany): Ludwigs-Maximilians-University; 2014.

21. Liang Y, Li Y, Sun K, Zhang Q, Li W, Zhu W, Zhang J, Fang J. Plasma thorns: Atmospheric pressure non-thermal plasma source for dentistry applications. Plasma Process Polym. 2015;12:1069-74.

22. TIGRES MEF technology [homepage on the Internet]. Marschacht, Germany: Tigres GmbH; c200515 [cited August 20 2016]. Available from: http://www.tigres-plasma.de/en/oberflaechentechnik-2/ mef-technology/.

23. Horn K, Schütte T, Struppert T, Beier O, Tölke T, Eckardt N, Schimanski A, Grünler B. Spectroscopic plasma monitoring deploying quality and process control to atmospheric pressure plasma applications. Jahrbuch Oberflächentechnik. 2012;68:85-97.

24. EMICON HR [homepage on the Internet]. Mering, Germany: PLASUS GmbH; c2017 [cited August 20 2016]. Available from: http://www.plasus.de/index.php?page=system_emicon_hr\&lang=de/.

Volume 7, Issue 2, 2017 